\title{
Larva migrans in the Oral Mucosa: Report of Two Cases
}

\author{
José Humberto DAMANTE ${ }^{1}$ \\ Luiz Eduardo Montenegro CHINELLATO ${ }^{1}$ \\ Fernando Toledo de OLIVEIRA ${ }^{1}$ \\ Cleverson Teixeira SOARES ${ }^{2}$ \\ Raul Negrão FLEURY ${ }^{2}$ \\ ${ }^{1}$ Department of Oral Medicine, Bauru Dental School, USP - University of São Paulo, Bauru, São Paulo, Brazil \\ ${ }^{2}$ Departament of Pathology, Lauro de Souza Lima Institute, Bauru, SP, Brazil
}

\begin{abstract}
Cutaneous Larva migrans is a very common disease in tropical regions. In the oral mucosa, the infection occurs in the same way as in the skin, but it is rarer. This report describes two cases of Larva migrans in the oral mucosa. The first case was in a 27 -year-old woman who presented an erythematous plaque located on the buccal mucosa, extending to a posterior direction, following a linear pattern, to other areas of the mouth. After incisional biopsy of the anterior-most portion of the lesion, morphological details obtained in multiple examined sections suggested Necator or Ancylostoma braziliense larvae as the cause of infection. The second case was in a 35 -yearold male who presented a fusiform erythematous plaque in the palatal mucosa. This area was removed and submitted to microscopic examination under a presumptive diagnosis of "parasite migratory stomatitis". The histological characteristics were suggestive of a larva pathway. In both cases the lesion disappeared after biopsy and the patients were symptom-free.
\end{abstract}

Key Words: Larva migrans, oral parasite, subcutaneous oral lesion.

\section{INTRODUCTION}

Domesticated or wild animals have many parasites whose infectious larvae are capable of completing their life cycle only inside their natural host. When these larvae infect a different host, including humans, they are usually not able to grow properly. In these cases, the larvae may migrate through the visceral or subcutaneous tissue, causing lesions in the skin or mucosa (1). Therefore, the term Larva migrans is used to describe the pathologies caused by migration of larvae that usually do not infect the human organism.

Visceral Larva migrans is rarer and normally affects the liver in conjunction with pulmonary infiltration. It is usually caused by a larva of the Toxocara genus (2). On the other hand, cutaneous Larva migrans is characterized by erythematous, pruriginous, and serpiginous lesions that are similar to a sinuous snakelike trace (3). Cutaneous Larva migrans is a self-limited disease because the larva cannot mature in the human organism, dying after 4 weeks (4).

The etiological agents found with greater frequency in these cutaneous infections are helminthes belonging to the Cestode and Nematode classes, especially Ancylostoma brasiliense and Ancylostoma caninum. These parasites are commonly found in the small intestine of dogs and cats (1).

These infections are more common in tropical countries and in Central and South America (1-4). Contamination usually occurs by direct contact of the skin or mucosa with contaminated surfaces, especially sand or vegetation, which are favored places for domestic animals to deposit their feces (3). The most frequently affected body parts are the feet, legs, buttocks, hands, and forearms (4). Although these parasites also infect mucosas, such as the oral mucosa, there are few reports in the literature about these cases (1-4).

In order to address this gap in the literature, this report describes two cases of Larva migrans found in the oral mucosa. 


\section{CASE REPORT}

\section{Case 1}

A 27-year-old female from a rural area was referred to our services by a dermatologist who requested a biopsy. The patient complained of oral canker sores that migrated in different directions in the mouth, producing an itching sensation and leaving her with the impression of a bug crawling in her mouth. When these lesions reached the throat, the patient reported significant discomfort, including dyspnea.

The lesion extended to a posterior direction in a linear pattern, crossing the retromolar trigone and soft palate, until it reached the anterior pillar of the opposite side of the tonsils (Fig. 1A). The oral inspection revealed an erythematous plaque located on the buccal mucosa, next to the right side of the lip commissure (Fig. 1B).

Incisional biopsy of the anterior-most portion of the lesion was performed (Fig. 1B) and showed the following microscopic aspects: oral mucosa constituted of stratified squamous epithelium with spongiosis, intraepithelial vesicles, and exocitosis. Under the epithelium, the lamina propria showed intense subacute inflammatory reaction, edema, fissures surrounded by hemorrhagic areas, mononuclear infiltrate, and numerous eosinophils (Fig. 2A).

In other areas seen in transversal sections, an intraepithelial tunnel containing a tubular-shape parasite with narrow lumen, compatible with a helminth larva, was identified (Fig. 2B, arrow). Morphologic details obtained in multiple examined sections suggested Necator or Ancylostoma braziliense larvae as the cause of infection as opposed to larvae such as Toxocara canis, Ascaris lumbricoides, and Strongiloides stercoralis. All of these helminthes can lead to the Larva migrans clinical manifestation, which was the final diagnosis in this case. The lesion spontaneously disappeared 1 week after biopsy.

\section{Case 2}

A 35-year-old male, non-smoker, working in a rural area, was referred to our service for examination of erythematous lesions in the oral mucosa. The lesions had appeared 3 months before examination and were recurrent and burning. The patients denied the occurrence of any systemic alterations in his medical history, mentioning only the occurrence of cutaneous "sandworms" and a habit of chewing grass or wood chips. Intraoral inspection revealed a linear lesion, continuous throughout almost the entire oral area. The lesion presented as a fusiform erythematous plaque that initiated in the right area of the palatal mucosa, crossed the palate to the left side, descended to the inferior anterior alveolar mucosa, and ended in the buccal mucosa on the right side (Fig. 3A,B).

In the buccal mucosa, in one of the extremities of the larva pathway, there was an area that was larger, more erythematous, more elevated, and mildly sensitive to palpation. This $3-\mathrm{cmm}$-wide fusiform area was removed and submitted to microscopic examination under a presumptive diagnosis of "parasite migratory stomatitis."

The histological sections demonstrated an oral mucosa fragment with mild epithelial hyperplasia. The subjacent stroma presented intense edema, erythrocyte overflow, and dilated vessels, as well as a mononuclear infiltrate with a large number of polymorphonuclear cells. The infiltrate affected the epithelium, leading to spongiosis and the development of vesicles with serosity, neutrophils, and eosinophils. Some areas had multiple vesicles that formed a reticular pattern (Fig. 4A). The subepithelial area presented abscesses amongst hyaline material, with a tubular larva (Fig. 4B, arrow). The histological characteristics were suggestive of a larva pathway, with possible fragments of the parasite. The lesion disappeared after incisional biopsy.

\section{DISCUSSION}

Cutaneous Larva migrans is a very common disease in tropical regions (1-4). Animals, especially dogs and cats, eliminate thousands of parasite eggs in their feces. In ideal temperature and humidity conditions, the eggs develop larvae. The larvae hatch and feed on organic matter and microorganisms in the soil. In approximately seven days, the larva reaches the infective state. In dogs and cats, the larvae reach sexual maturity within approximately 4 weeks. In the human body, the larvae actively penetrate through the skin and migrate through the subcutaneous area for weeks or months and then eventually die (1).

Larva migrans in oral mucosa is rare (1-5), but the infection occurs in the same way as in the skin, i.e., through direct contact with surfaces contaminated with larvae. In the two reported cases, patients may have been infected due to the lack of adequate hygiene of the hands 
and other body parts that could contact contaminated dirt. The grass-chewing habit, which is common among rural workers, is another contamination source, and it was reported in Case 2. Capuano et al. (3) reported a case of a patient from a rural area who had dogs and cats in their backyard and who would eat fruits that had fallen on the ground without washing them.

Jaeger et al. (2) reported another case in which the infection probably occurred through direct contact with surfaces contaminated with dog and cat feces. The authors stated that the inoculation of the parasite might have occurred because the patient, who was a fisherman, used to hold fishing hooks between his lips, and these objects had had contact with beach sand.

Regarding the clinical manifestation, the first symptom is an erythematous papule at the larva penetration site, which then evolves into a vesicle. Along its migration route, the larva produces intense itching. In older cutaneous lesions, crusts are formed, leaving a dark line that later disappears $(1,5)$.

The clinical manifestation is the same in oral mucosa. In the case reported by Capuano et al. (3), the lesions were originally composed of vesicles on the palate and rapidly transformed into migratory
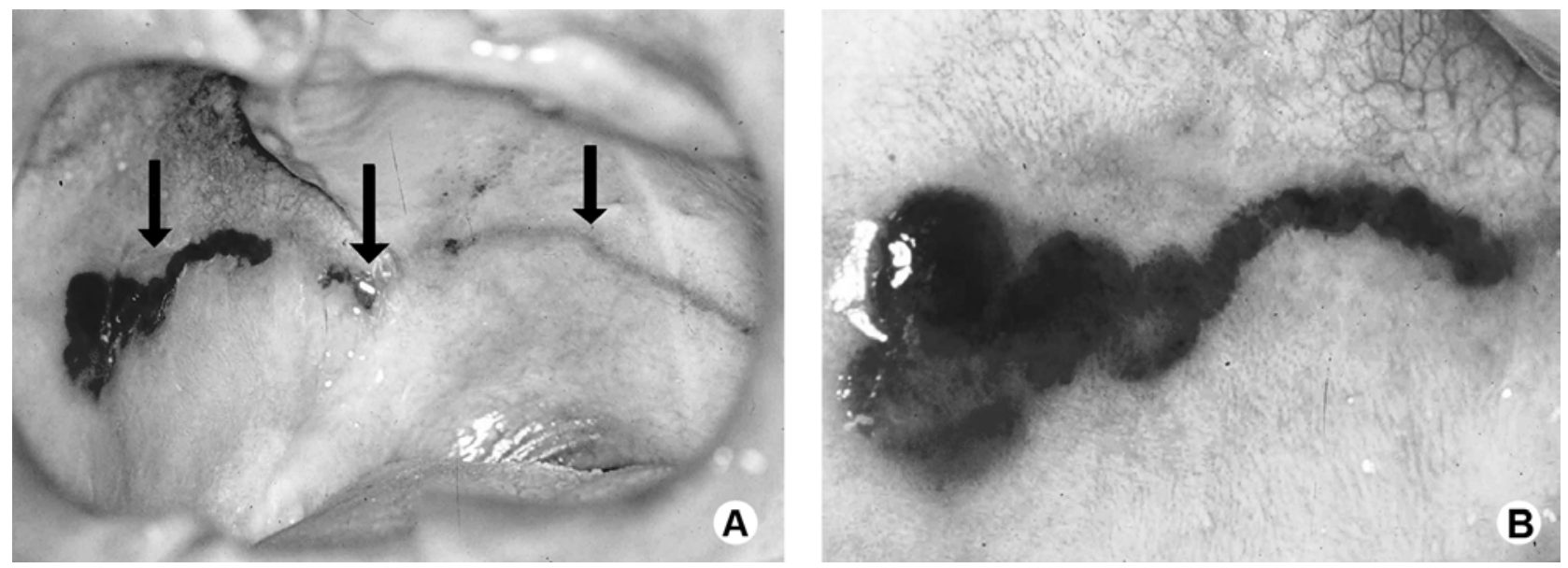

Figure 1. Clinical images of Case 1. A= Erythematous linear spot on the soft palate continuing as a linear erythematous plaque on the buccal mucosa, on the right side; $\mathrm{B}=$ Detail of the anterior portion of the lesion. Emphasis on the hemorrhagic aspect.
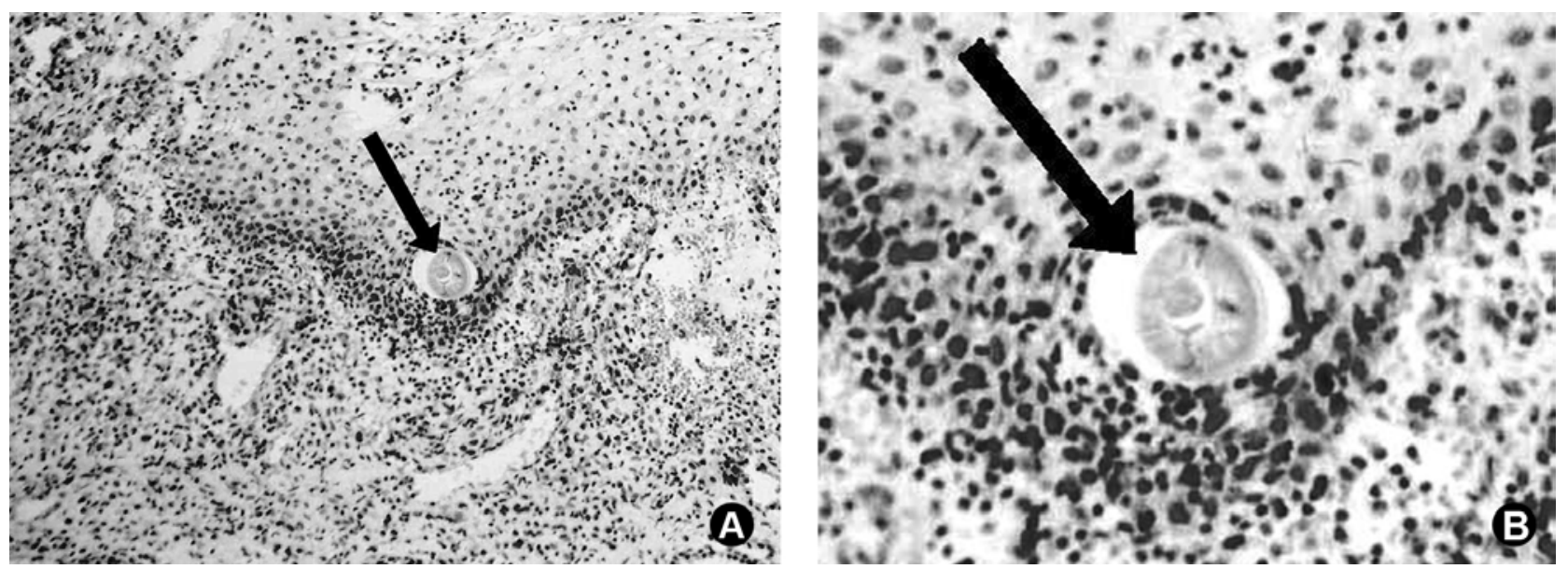

Figure 2. Photomicrographs of Case 2. A = Oral mucosa with intense subacute inflammatory reaction, erythrocyte overflow, lymphocyte predominance, and a large number of eosinophils. Presence of rounded eosinophilic structure compatible with parasite; B = Detail indicating probable anterior extremity of the parasite, with tubular structure and narrow lumen. 
and pruriginous lesions in several areas of the mouth. Although the larva can migrate a reasonable distance, it is generally confined to a small territory. In some cases $(3,4)$, lesions are extensive, leaving a pathway in various areas of the oral cavity, possibly due to more than one infecting parasite.

In the human body, larvae are not able to maturate and die between 4 and 8 weeks after infection. Therefore, this is a self-limited disease. In some cases, there may be hypersensitivity to the parasite, with the development of urticaria and local edema (4). In addition, there may be discomfort associated with the symptoms, such as dyspnea when lesions reach the throat, as reported by the patient in Case 1.

The diagnosis of Larva migrans is primarily clinical, i.e., based on signs and symptoms. However, because its presentation in the oral mucosa is rare, incisional biopsy of the newest portion of the lesion is recommended. This enables the parasite to be detected, as in Case 1.

The larva belongs to the Cestode or Nematode classes $(4,6)$. The main etiological agents are Ancylostoma brasiliense and Ancylostoma caninum, which are parasites of the small intestine of dogs and
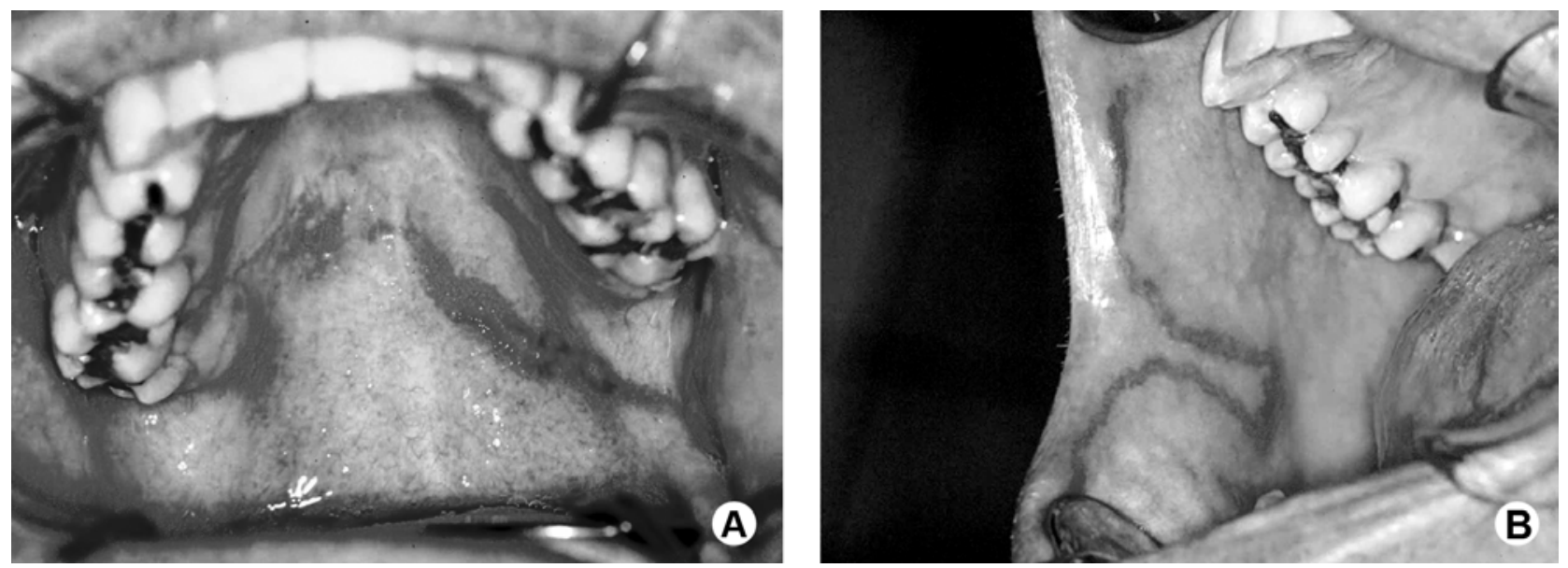

Figure 3. Clinical images of Case 2. A = Linear erythematous plaque crossing the palate; $\mathrm{B}=$ Anterior portion of the lesion affecting the lip area and the buccal mucosa.
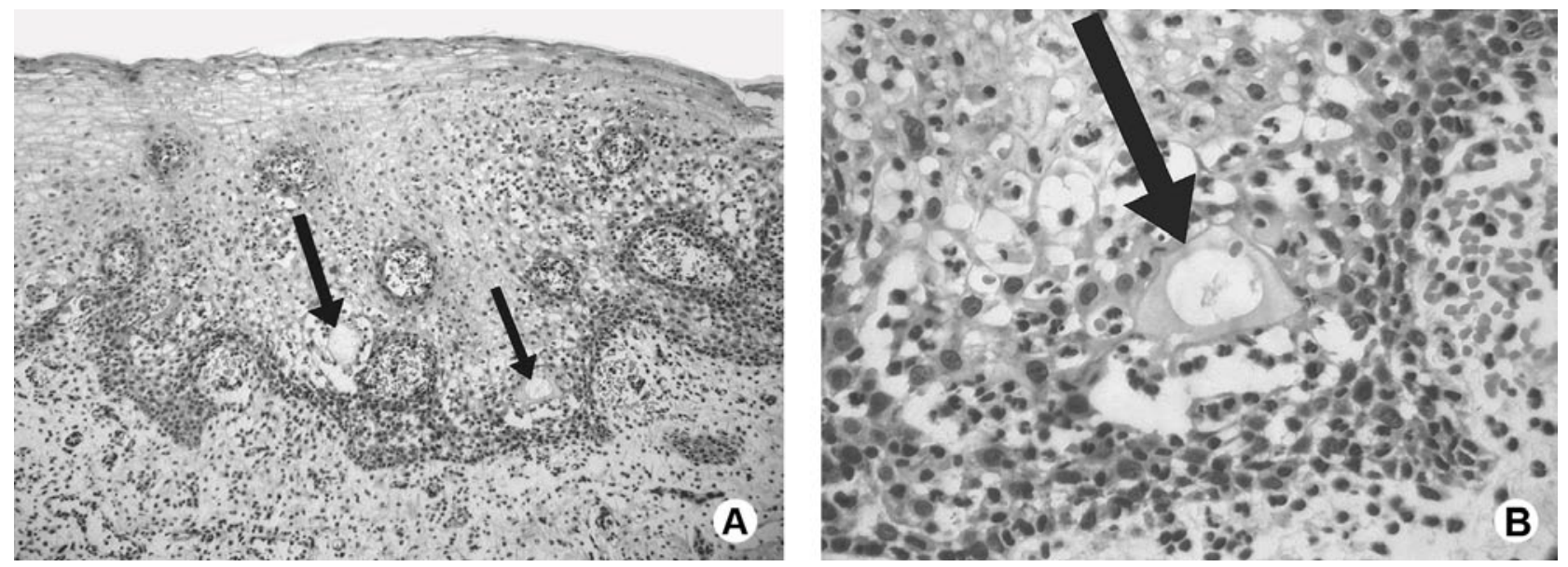

Figure 4. Photomicrographs of Case 2. A = Oral mucosa with epithelial hyperplasia; hemorrhagic areas and subepithelial inflammatory infiltrate; and exocytosis. Suprabasal tubular structures (arrow). B = Detail showing eosinophilic-contour tunnel with fragment of amorphous structure that is compatible with parts of the parasite (arrow). Emphasis on the mononuclear inflammatory infiltrate and on the large number of eosinophils. 
cats. However, other parasites such as Ancylostoma ceylonicum, Uncinaria stenocephala, Bubostomum phebotomum, Gongylonema species, Anatrichosoma cutaneum, Strongyloides stercoralis, and Necator americanus can also cause the disease (4). In Case 1, the morphologic characteristics of the parasite were compatible with Necator americanus or Ancylostoma brasiliense. Similar to the cases presented by other authors $(2,3)$, the histopathological examinations did not allow us verifying the nature of the larva with certainty, although some measurements and morphologic characteristics matched the ones observed for Ancylostoma larvae.

Although cutaneous Larva migrans is a selflimited disease because the larvae cannot mature and dies within a few weeks, the majority of the authors recommend treatment (1-4). The treatment may be surgical, with either an excisional (4) or an incisional biopsy, as performed in the two cases described in the present report. Topic or systemic drug therapy is also an option $(1,4)$. In extensive cases with multiple lesions, the systemic use of albendazole or thiabendazole is recommended. In a previous oral Larva migrans case (4), the lesion healed completely with systemic use of thiabendazole ( $25 \mathrm{mg} / \mathrm{kg}$ twice a day for 5 days).

Finally, although oral Larva migrans is not severe, it is a rare disease. Therefore, the reporting of new cases is necessary so that lack of knowledge does not compromise the diagnosis and treatment of patients.

\section{RESUMO}

Larva migrans cutânea é uma doença muito comum em regiões tropicais. Na mucosa oral, a infecção ocorre da mesma forma como na pele, mas é raro. Este relato descreve dois casos de Larva migrans na mucosa oral. O primeiro caso foi de uma mulher de 27 anos de idade, que apresentou uma placa eritematosa localizada na mucosa julgal, estendendo-se posteriormente, em conformação linear, para outras áreas da boca. Após biópsia incisional da porção mais anterior da lesão, detalhes morfológicos obtidos em múltiplos cortes examinados sugeriram Necator ou larvas de Ancylostoma braziliense como a causa da infecção. $\mathrm{O}$ segundo caso foi de um homem de 35 anos de idade que apresentou uma placa fusiformes eritematosas na mucosa palatina. Esta área foi removida e submetida a exame microscópico, com diagnóstico presuntivo de "estomatite migratória por parasita". As características histológicas foram sugestivas de trajeto de larva. Em ambos os casos a lesão desapareceu após a biópsia e os pacientes estavam assintomáticos.

\section{REFERENCES}

1. Andre J, Bernard M, Ledoux M, Achten G. Larva migrans of the oral mucosa. Dermatologica 1988;176:296-298

2. Jaeger RG, Araújo VC, Marcucci G, Araújo NS. Larva migrans in the oral mucosa. J Oral Med 1987;42:246-247.

3. Capuano ACT, Sousa SCOM, Carvalhosa AA, Pinto Junior DS. Larva migrans in the oral mucosa: Report of case. Quintessence Int 2006;37:721-723.

4. Lopes MA, Zaia AA, Almeida OP, Scully C. Larva migrans that affect the mouth. Oral Surg Oral Med Oral Pathol 1994;77:362367.

5. Hansen LS, Allard RHB. Encysted parasitic larvae in the mouth. J Am Dent Assoc 1984;108:632-636.

6. Lambertucci JR, Rayes A, Serufo JC, Teixeira DM, GerspacherLara R, Nascimento E, et al.. Visceral Larva migrans and tropical pyomyositis: A case report. Rev Inst Med Trop S Paulo 1998;40:383-385. 